\title{
Los molinos verticales en la industria del cemento
}

\author{
Dr. Ing. JUAN M. HIDALCo DE CISNEROS ALONSO
}

Loesche Española de Ingeniería, S. L.

Con ocasión de los $\mathrm{V}$ Coloquios de Directores y Técnicos de fábricas de cemento tuvimos la oportunidad de exponer a Vds. lo que entonces era una pequeña visión de futuro dentro del marco de la utilización de los molinos verticales o de rodillos para la molienda de crudo de cemento, destinado a la alimentación de hornos de gran producción, y utilizando el calor contenido en los gases de salida para realizar, durante la molienda, y en el interior del molino, el proceso de secado del crudo.

Han pasado seis años y lo que entonces se dijo se ha visto ampliamente confirmado por la realidad de unas instalaciones que hoy se reparien por todo el mundo. La tendencia general hacia el molino vertical se hizo evidente en el instante en que la industria del cemento evolucionó hacia plantas cada vez más grandes con hornos rotativos trabajando en combinación con intercambiadores de calor. Hornos con capacidades de hasta casi $10.000 \mathrm{t}$ /día son alimentados por molinos de rodillos. En la figura 1 les hemos hecho un resumen de las fábricas que en este período de tiempo se han realizado con molino vertical y hornos de más de $3.000 \mathrm{t} /$ día, indicando en ella el suministrador del horno y el del molino.

Fábricas de cemento de 3.000 t/día o más con molino vertical

\begin{tabular}{llll}
\hline \multicolumn{1}{c}{ F I R M A } & P A I S & H O R N O & M O L I N O \\
\hline 1. Ste. des Ciments Francais & Francia & Polysius & Pfeiffer \\
2. SA des Ciments Vicat & Francia & Polysius & Loesche \\
3. Buderus'sche Eisenwerke & Alemania & Humboldt & Pfeiffer \\
4. Portland-Zementwerke Heidelberg AG & Alemania & Polysius. & Loesche \\
5. Maerker Zementwerke GmbH & Alemania & F. L. S. & Pfeiffer \\
6. Nordzement AG & Allemania & Humboldt & Loesche \\
7. Readimix Zement Werke & Alemania & Humboldt & Pfeiffer \\
8. General Cement Company & Grecia & I H I & Loesche \\
9. Cementir-Cementerie dell Tirreno S.p.A. & Italia & F. L. S. & Loesche \\
10. Aslan ve Eskihisar Muttehit Cimento ve su & Turquía & Polysius & Loesche \\
11. Lafarge-Lonestar & U. S. A. & Allischalmers & Loesche \\
12. Fars and Khuzestan Cement Co. & Irán & Polysius & Pfeiffer \\
13. Chichibu & Japón & I H I & Loesche \\
14. Toyo-Soda I & Japón & I H I & Loesche \\
15. Toyo-Soda II & Japón & H I & Poesche \\
16. Nihon-Cement & Japón & Polysius/Mitsubisi & Loesche \\
17. Aso-Cement & Japón & Loesche \\
18. Sumitomo Cement & Japón & H I & Loesche \\
19. Ube Cement & Japón & UBE/Kawasaki & Loesche \\
20. Ube Cement & Japón & UBE/Kawasaki & Loesche \\
21. S. N. M. C. & Argelia & Kawasaki & Lcesche \\
22. Cement Limited & Irlanda & F. L. S. & Pfeiffer (1977) \\
23. National Cement Company & Libia & Fives Lille & Pfeiffer (1977) \\
24. S. N. M. C. & Argelia & Kawasaki & Loesche (1977) \\
\hline
\end{tabular}

Fig. 1 


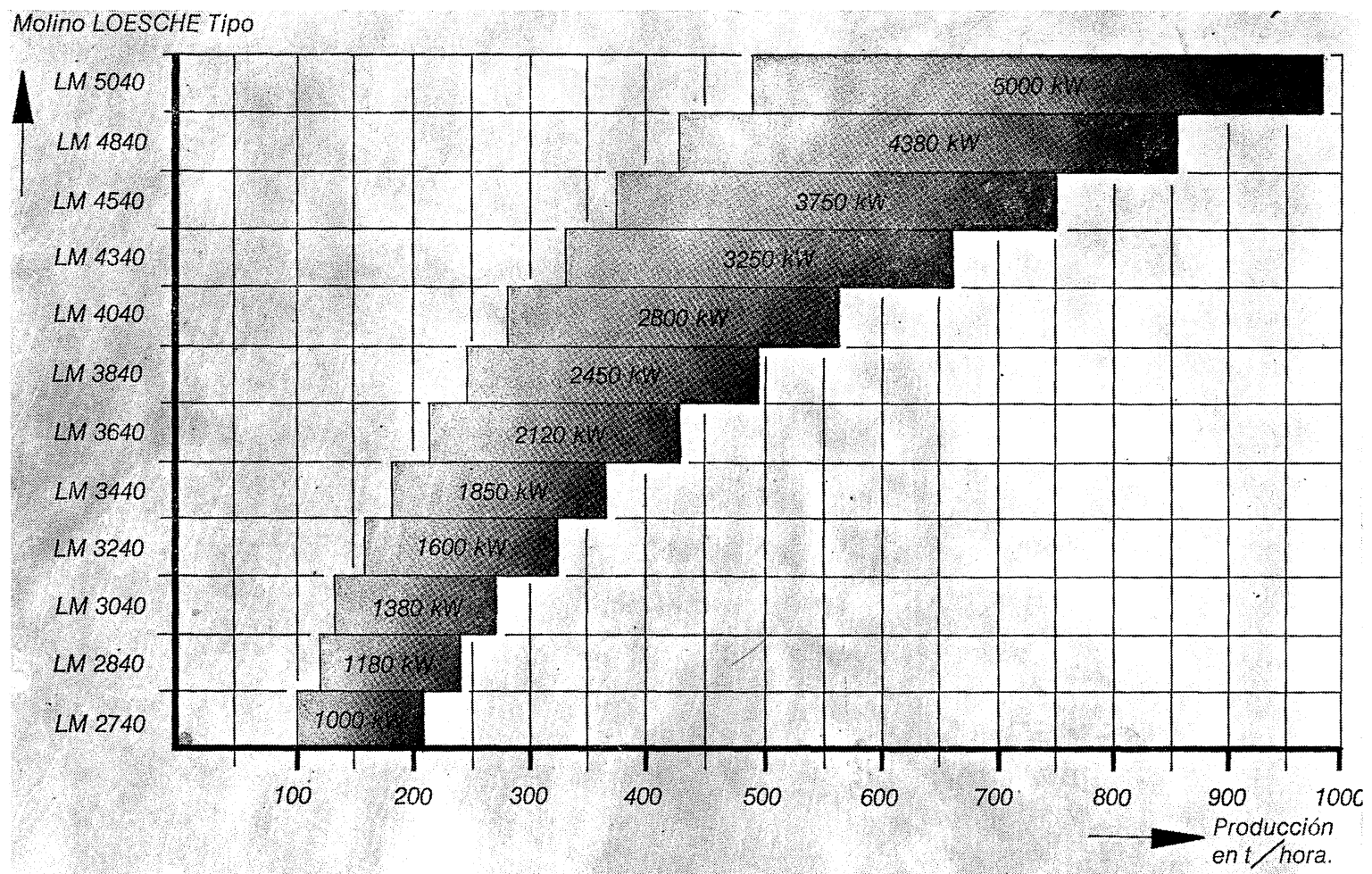

Molino de rodillos LOESCHE.

Programa de tipos, zonas de producción

y accionamientos instalados.
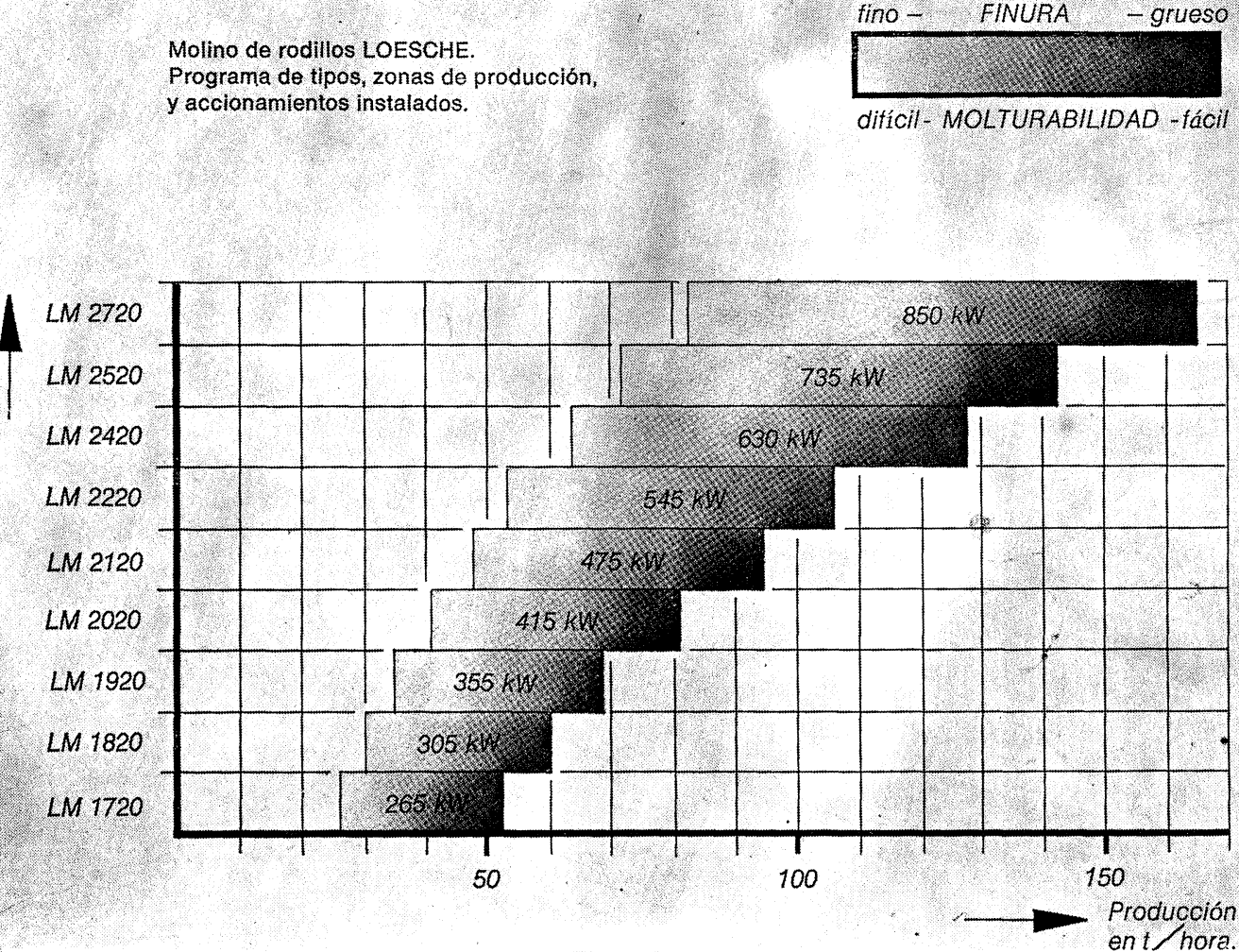

Fig. 2

El crecimiento que se ha experimentado en el tamaño y capacidad de producción de los hornos ha ido acompañado por un crecimiento similar en los molinos verticales. Si hace diez años un molino de $80 \mathrm{t} / \mathrm{h}$ era ya grande, hace cinco años se hablaba ya de las 150 $\mathrm{t} / \mathrm{h}$ y hoy en día se trabaja con producciones de $420 \mathrm{t} / \mathrm{h}$ y a nadie asusta hablar de unidades de hasta $650 \mathrm{t} / \mathrm{h}$ o más (fig. 2). 
¿Qué ha pasado? ¿Por qué este cambio en el tradicional sistema de molienda de crudo?

La utilización del molino de rodillos o del de bolas es, en realidad, un concepto distinto a la hora de proyectar una fábrica de cemento. No es posible comparar ambos molinos, considerándolos como elementos aislados, sino que hay que comparar dos sistemas distintos de producción de clínker.

Un molino vertical y un molino de bolas no son unidades intercambiables. Cada uno de ellos exige un proyecto diferente, al ser también distintas las condiciones en las que se va a desarrollar la molienda; y si se proyecta bajo la base de conseguir una rentabilidad máxima de toda la fábrica hay que tener en cuenta al molino vertical, ya que es el único que permite una integración total en el sistema de regulación de la planta, como veremos más adelante.

¿No decían que el molino vertical sólo sirve para determinado tipo de materiales?

¿Pueden estos molinos responder mecánicamente a las exigencias que de ellos se solicitan?

\section{¿Qué pasa con el desgaste de los elementos de molienda?}

\section{¿Dónde están las ventajas?}

\section{¿Por qué?}

Si nos lo permiten, señores, vamos a tratar de ir dando respuesta a todas y a cada una de estas preguntas, pero empezando por ésta última:

¿Por qué?

Porque la elevación del costo de la energía ha inducido a las empresas a reconsiderar sus tradicionales procesos de fabricación, obligándoles a aplicar aquéllos que aseguren una mayor rentabilidad.

Porque el desarrollo alcanzado por los sistemas de precalcinación ha permitido llegar a unas producciones de clínker en hornos relativamente pequeños que pueden llegar a duplicar las de los hornos convencionales, y había que buscar los molinos más adecuados para esas producciones.

Porque las dificultades de mantener la rentabilidad de los procesos por vía húmeda son cada vez mayores y era necesario encontrar soluciones al problema.

Porque las legislaciones cada vez más severas en todos los países obligan a realizar grandes inversiones para proteger el medio ambiente, y había que instalar las máquinas que redujeran al mínimo estas inversiones.

Porque los aumentos constantes del costo de la mano de obra exigen reducir personal y hay que llegar al grado de automatización óptimo que permita mejorar la productividad.

¿Dónde están las ventajas?

Vamos a enumerar algunas de ellas:

1. Una simplificación del sistema, al poder hacer pasar por el molino la totalidad de los gases de salida del horno (fig. 3). 
2. Una posibilidad de secado y molienda simultáneos, utilizando todo el calor aportado por dichos gases.

$\mathrm{Si}$ tenemos en cuenta que éstos llegan al molino con aproximadamente $330^{\circ} \mathrm{C}$ de temperatura, comprobaremos que mediante este sistema se puede eliminar aproximadamente un $8 \%$ de humedad en el crudo, para una producción de molino que permita alimentar el horno con un margen suficiente de seguridad. Si la humedad fuera superior, habría que acudir a un hogar auxiliar de alta temperatura, pudiéndose secar materiales con hasta un $20 \%$ de humedad.

$\mathrm{Si}$, por el contrario, la humedad fuese inferior, es aconsejable la inyección de agua para mejorar el punto de rocío del electrofiltro.

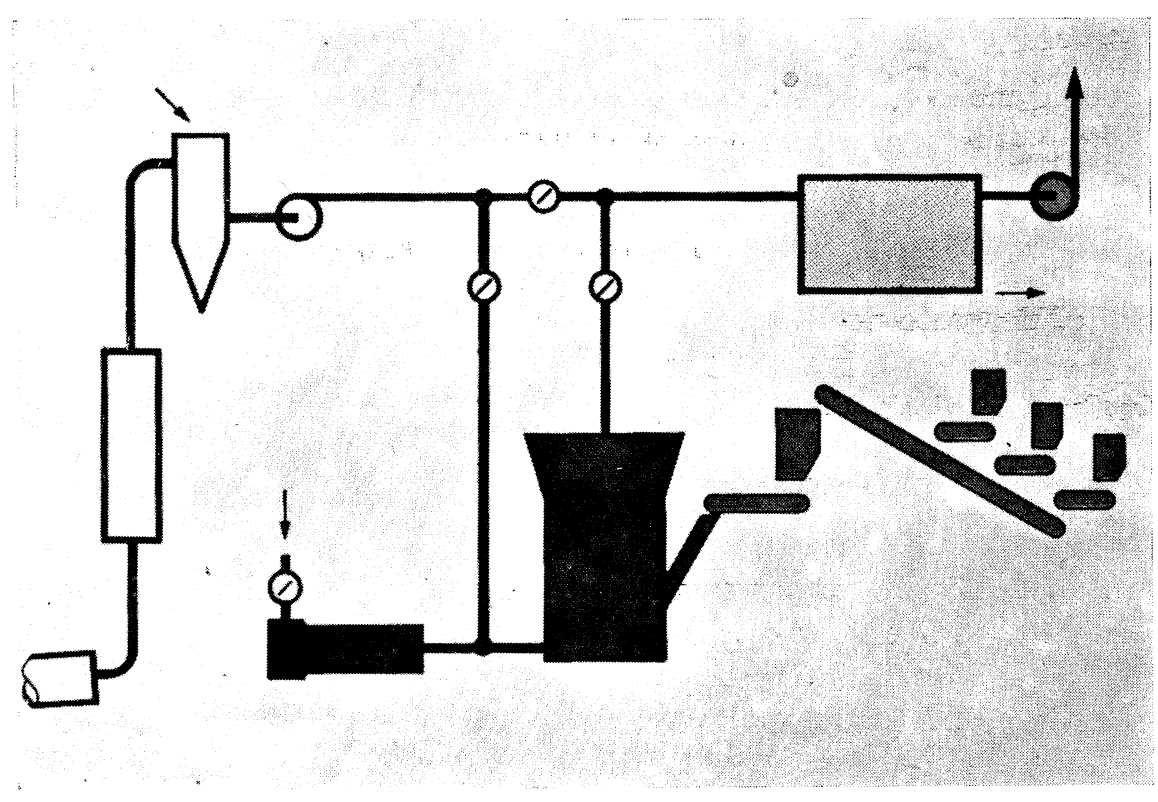

Fig. 3

3. Un menor consumo de energía por $t$ molida, que viene a representar un ahorro de un 10 a un $25 \%$ con respecto a los molinos de bolas cuando se trata de materiales fácilmente molturables, aumentando esta diferencia hasta un 25-30\% en los crudos de alta dureza y difícil molturabilidad.

4. Unos menores costos de inversión para los equipos que comprenden la planta, incluyendo los motores, tuberías, despolvorización, elementos de transporte, válvulas, tajaderas, etc., a los que hay que añadir el ahorro considerable que se produce en los equipos eléctricos al ser menor la potencia instalada y el número de accionamientos, así como la simplificación de la obra civil y la cimentación.

5. Una mayor posibilidad de automatización debido a la rápida respuesta de estos molinos, como consecuencia a su poca carga, que les premite reaccionar en 2,5 min. a los cambios de composición de crudo que se hagan en la dosificación, eliminando así una inercia en el proceso de automatización que en los molinos de bolas puede llegar a ser de 10 a 20 veces mayor.

Durante los últimos coloquios se habló ampliamente sobre este tema, y, no cabe du$\mathrm{da}$, de que este punto ha influido de forma determinante en la introducción de los molinos verticales en el proceso de la molienda del crudo. 
Si sobre los 2,5 min. antes mencionados, calculamos 1,5 min. para el transporte del crudo hasta el tomamuestras, tendremos un intervalo de 4 min. para hacer las correcciones.

Utilizando un aparato de rayos $\mathrm{X}$ que pueda realizar los análisis en este período de tiempo, tendremos la posibilidad de una corrección casi en continuo, que nos lleve a la obtención de un crudo que, prácticamente, no necesitaría ser homogeneizado.

En la mayoría de los casos sería suficiente instalar un monitor de calcio que mediante isótopos de hierro determine, de forma lineal, el contenido en $\mathrm{CaO}$, y que regule las básculas dosificadoras en cuanto se produzca una desviación sobre el valor nominal. Este aparato debería considerarse ya hoy como parte integrante de la instalación de molienda.

Las nuevas normas con exigencias cada vez mayores en cuanto a la calidad del cemento requieren una homogeneidad del clínker, que solamente se consigue a base de un control exhaustivo de todas las fases de fabricación entre las que ocupa un lugar preponderante la preparación del crudo. Los molinos verticales han contribuido a facilitar esta labor gracias a la rapidez de respuesta a la que antes hemos hecho mención.

6. La protección del medio ambiente.

Es éste un capítulo que cada día adquiere mayor importancia.

La emisión de polvo al exterior queda controlada dentro de las normas, por medio del electrofiltro, ya que toda la instalacción trabaja en depresión, pero existe un momento crítico que es cuando se pasa de marcha directa a marcha combinada. Los gases cargados de polvo que proceden del horno, y que son humedecidos en la torre de enfriamiento, no pueden hacerse pasar por el molino sin un previo calentamiento de éste, puesto que se producirían problemas de condensación en el mismo. El tiempo necesario para ello desaparece al tratarse de un molino vertical, pues su poca carga no exige ningún tipo de precalentamiento.

El nivel sonoro es otro de los factores que hoy en día más se controla, siendo precisamente aquí donde los molinos verticales ofrecen grandes ventajas.

El Dr. Sillem pronunció una interesante conferencia sobre niveles sonoros, con ocasión del Simposio sobre trituración celebrado en Düsseldorf en mayo de este año. En la figura 4 vemos unas curvas comparativas entre un molino de bolas y un molino de rodillos. El espectro sonoro de estos últimos se encuentra situado entre los 70 y los $95 \mathrm{~dB}$, frente a los 90-105 dB de los molinos de bolas, dándose la circunstancia de que en los molinos verticales el nivel sonoro más alto es el del motor con 85-100 $\mathrm{dB}$.

Como los molinos no se pueden aislar para no entorpecer su mantenimiento, es necesario cerrar herméticamente todo el edificio, construyéndolo sin ventanas y con puertas especialmente estancas, con el consiguiente problema de la refrigeración del aire del local, a través de silenciadores. Se comprende, pues, que el nivel sonoro del molino puede tener una fuerte repercusión en la inversión total de la planta de molienda.

Estas son algunas de las ventajas de estos molinos, pero pasemos a la siguiete pregunta:

\section{¿Qué pasa con el desgaste de los elementos de molienda?}

Para proyectar una instalación hay que realizar primero una prueba de molturabilidad con una muestra representativa de las materias primas. Se efectúa este ensayo en un 
molino de laboratorio y se determina en primer lugar el factor de molienda, que es el que da el grado de molturabilidad del material y permite elegir el tipo de molino a utilizar, de acuerdo con la potencia necesaria para el proceso de molienda y el volumen de gases que deberán de atravesar el molino.

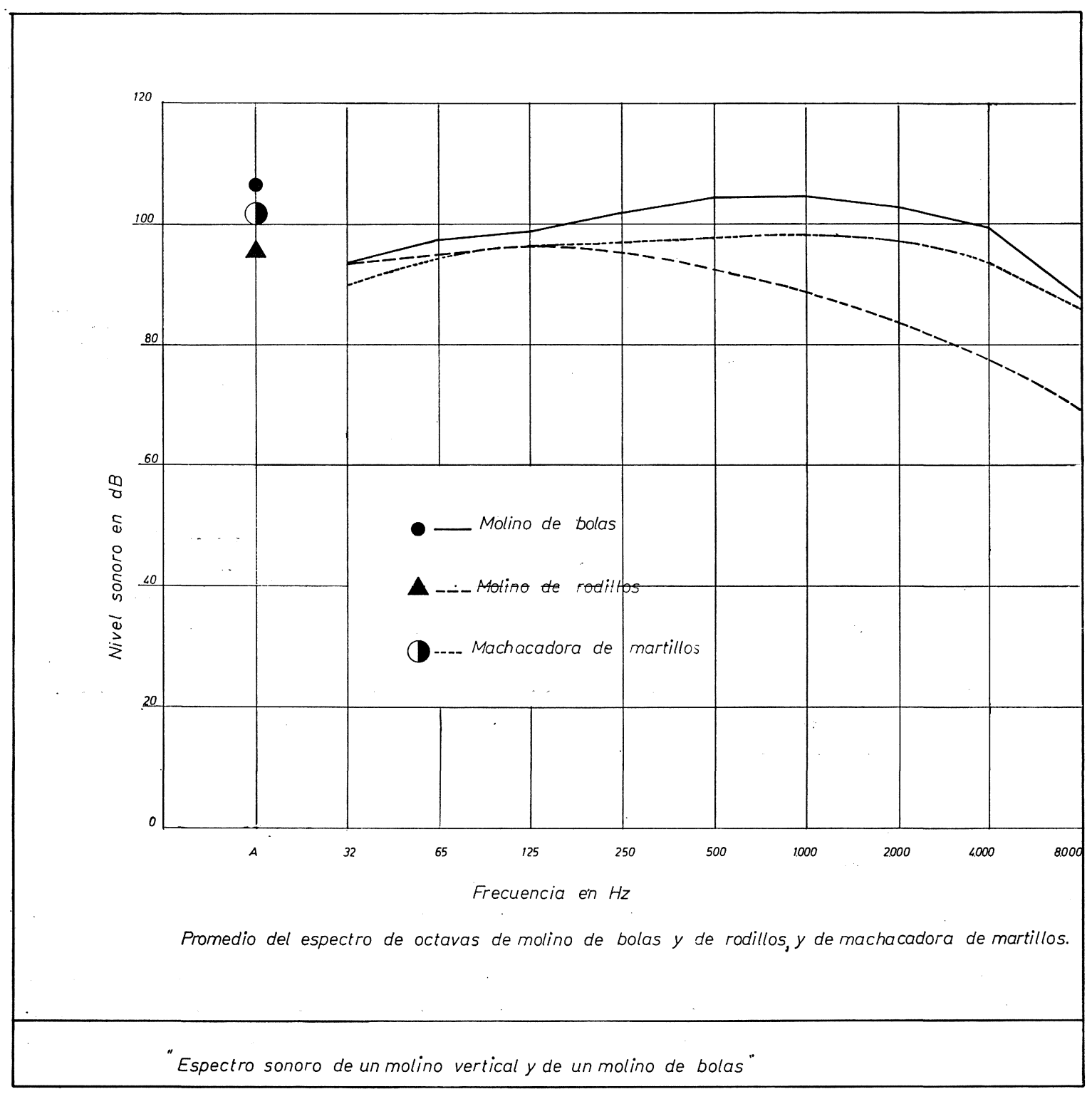

Fig. 4

Se traza la curva granulométrica correspondiente a dicho material (fig. 5), y se hace un balance térmico que fija en todos sus detalles las constantes térmicas y volumétricas de la instalación, sobre las que se basan las garantías de producción y consumo.

Aprovechando estos ensayos se realiza también un test de desgaste de las piezas o elementos de molienda.

La experiencia demuestra que los elementos de desgaste de los molinos verticales resultan un poco más costosos, en precio por $\mathrm{kg}$, que los correspondientes a los molinos de bolas, si bien presentan un desgaste, en $\mathrm{g} / \mathrm{t}$, inferior al de estos molinos, equilibrándose lós costos brutos de desgaste por t para ambos tipos de instalaciones. 
Los costos por desgaste aumentan en ambos casos de forma similar al ser mayor la abrasividad del material, debido principalmente a la influencia de los componentes ricos en sílice.

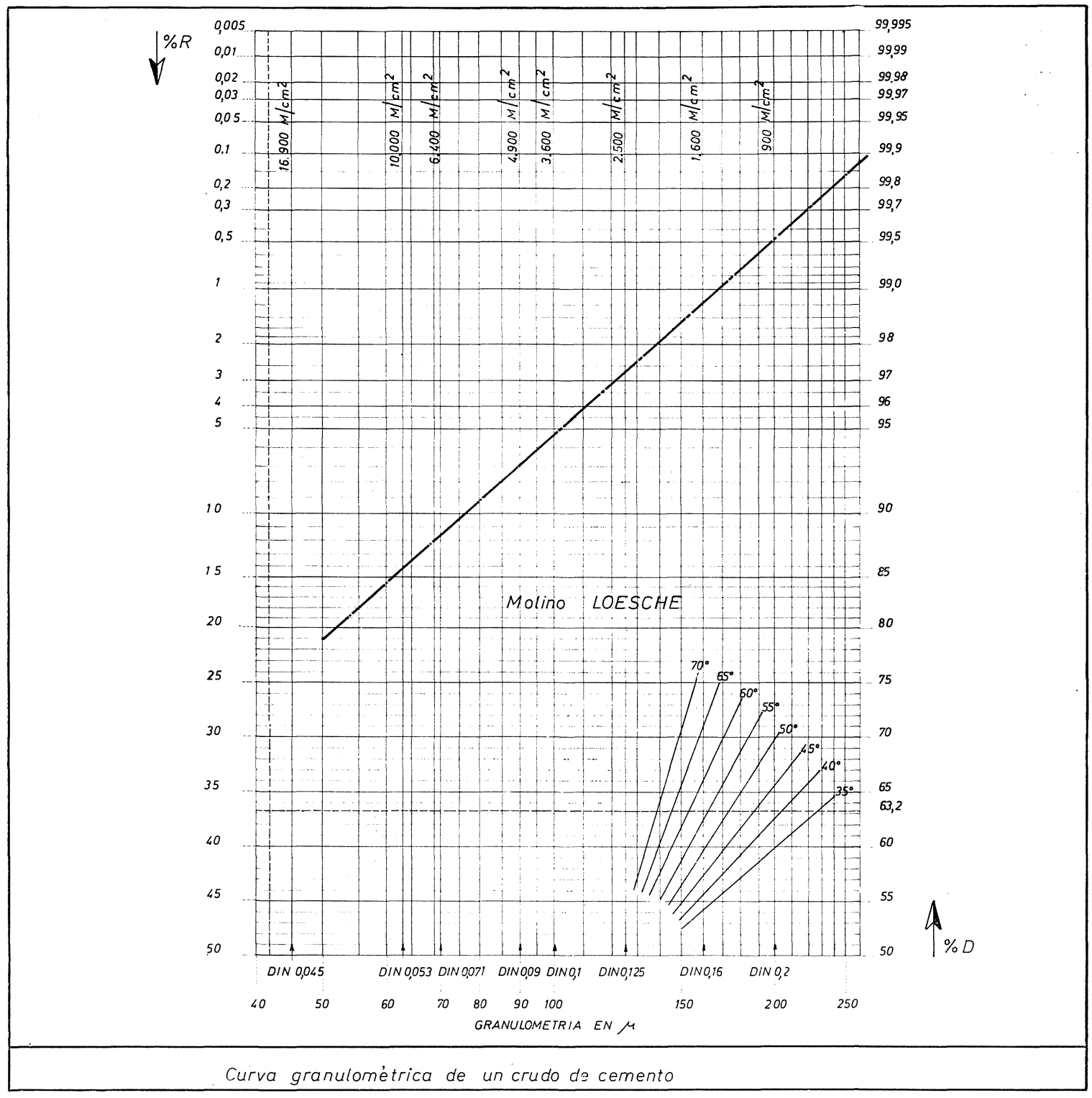

Fig. 5

Para determinar la influencia del desgaste en los costos de molienda, se hizo en un molino vertical, con capacidad para $240 \mathrm{t} / \mathrm{h}$, un estudio detallado del reparto proporcional de dichos costos entre los diversos factores, obteniéndose el siguiente resultado:

- Consumo de energía

- Amortización de los equipos

- Amortización de la obra civil

- Desgaste

- Mantenimiento

$\%$
64,2
23
8,5
1,6
2,7

Se deduce de estas cifras que los costos por desgaste tienen una incidencia mínima sobre los costos de molienda (1,6 \%), si se comparan, por ejemplo, con el consumo de energía, que representa el $64,2 \%$. 
Hay que pensar que los molinos verticales nacieron para moler carbón, cuya abrasividad es muy superior a la del crudo de cemento, y que otra aplicación de los molinos verticales es la molienda de clínker, yeso y puzolanas. Pruebas realizadas a nivel industrial con un molino grande en una fábrica de cemento han confirmado la posibilidad de un ahorro de energía, con respecto al molino de bolas, del 10-25 \% en ia molienda de clínker para cementos de buena calidad. Este menor consumo tiene su explicación en que el molino vertical produce menos finos que el de bolas, y estos finos, en cuanto están molidos, son arrastrados por la corriente de aire a través del separador.

La máxima concentración de partículas en un cemento molido con molino de rodillos está situada alrededor de los 20 micrones, mientras que esta concentración se produce alrededor de los 5-7 micrones en el molino de bolas, pudiéndose conseguir las mismas resistencias a los 28 días moliendo el cemento en el molino vertical con valores de superficie específica (Blaine) notablemente más bajos. Así, por ejemplo, para obtener un buen cemento P-450 basta moler hasta aproximadamente 2.000 Blaine en un molino vertical, siendo necesario pasar de los 3.000 Blaine en el molino de bolas. El desgaste de las camisas y la pista es en este caso, del orden de los $10 \mathrm{~g} / \mathrm{t}$ de cemento molida.

Es interesante hacer notar que, al ser el molino vertical un molino en corriente de aire, permite ser alimentado con el clínker caliente directamente desde el horno, bajando la temperatura del mismo en breves momentos hasta los $100^{\circ} \mathrm{C}$ y menos, por efecto del aire frío que penetra en el molino a través de la corona de álabes. La despolvorización del sistema no presenta ninguna dificultad, realizándose en estos momentos pruebas de molienda a gran escala con resultados muy esperanzadores.

¿Pueden estos molinos responder mecánicamente a las exigencias que de ellos se solicitan?

Una pequeña descripción del estado actual de la técnica para la construcción de los molinos verticales debe responder a esta pregunta.

La incorporación al mercado de los molinos de cuatro rodillos en ejecución modular, uno de los cuales aparece en la figura 6, fue un paso definitivo en el proceso de ampliar la capacidad de producción de los mismos.

Las presiones de molienda cada vez mayores obligaron a un aumento constante en el diámetro de los rodillos, pero al repartirse los esfuerzos entre cuatro rodillos disminuyó de nuevo el diámetro de los mismos.

La construcción modular ha facilitado la fabricación y principalmente el transporte de las grandes unidades que ahora son montadas en obra, y ha permitido sobre todo el poder adaptar en cada caso la carcasa del molino al volumen de gases que pasan a través del mismo.

El esfuerzo de molienda se consigue mediante un sistema oleohidráulico que se utiliza también para elevar los rodillos sobre la pista, a fin de que el arranque se haga en vacío, con lo cual se facilita la utilización de motores de arranque directo. La figura 7 muestra, esquemáticamente, el funcionamiento de este sistema.

Para determinar el tipo o tamaño del molino deberán tenerse en cuenta el esfuerzo de molienda necesario, que es función del factor de molturabilidad; la producción y la finura deseadas, así como el volumen de gases que pasarán por el molino y la humedad del crudo.

Los reductores para la maquinaria destinada a trabajar en las fábricas de cemento, y en especial los reductores de los molinos de crudo y de cemento, así como los de los hornos, han requerido siempre de sus fabricantes una atención especial, como consecuencia 
de las exigencias técnicas y constructivas de los mismos. De la misma forma que hoy se fabrican ya reductores o accionamientos para la industria del cemento, con potencias de hasta $10.000 \mathrm{~kW}$, pueden fabricarse también reductores para los molinos verticales, con potencias que por ahora llegan hasta los $5.000 \mathrm{~kW}$, y de hecho, funcionan ya molinos con reductores de eje de salida vertical y una potencia de $3.000 \mathrm{~kW}$.

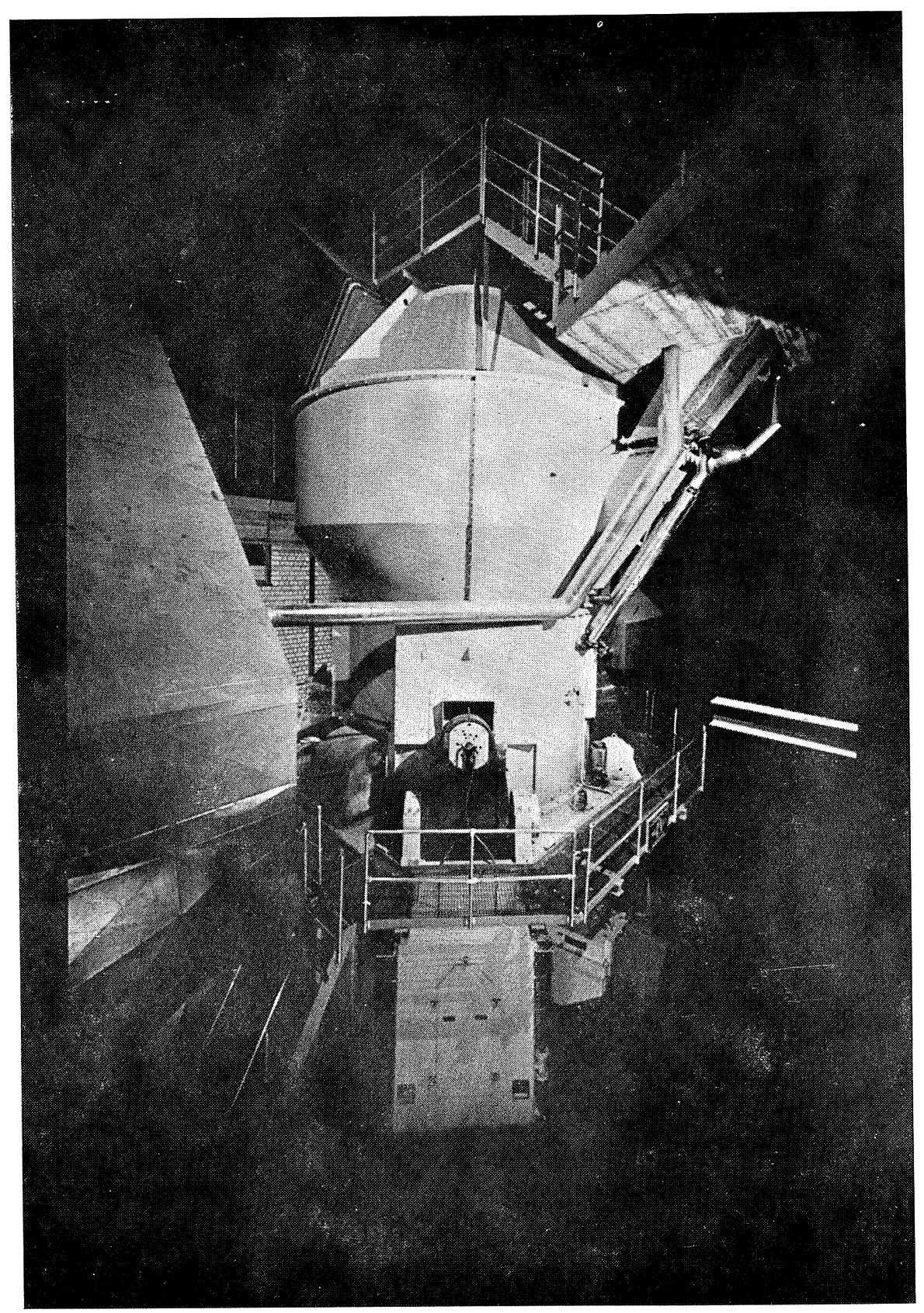

Fig. 6

En la figura 8 podemos ver el funcionamiento esquemático de un molino vertical. El material que llega al molino desde la dosificación cae sobre la pista que se asienta sobre el plato, y éste, a su vez, sobre el reductor, girando con él. 


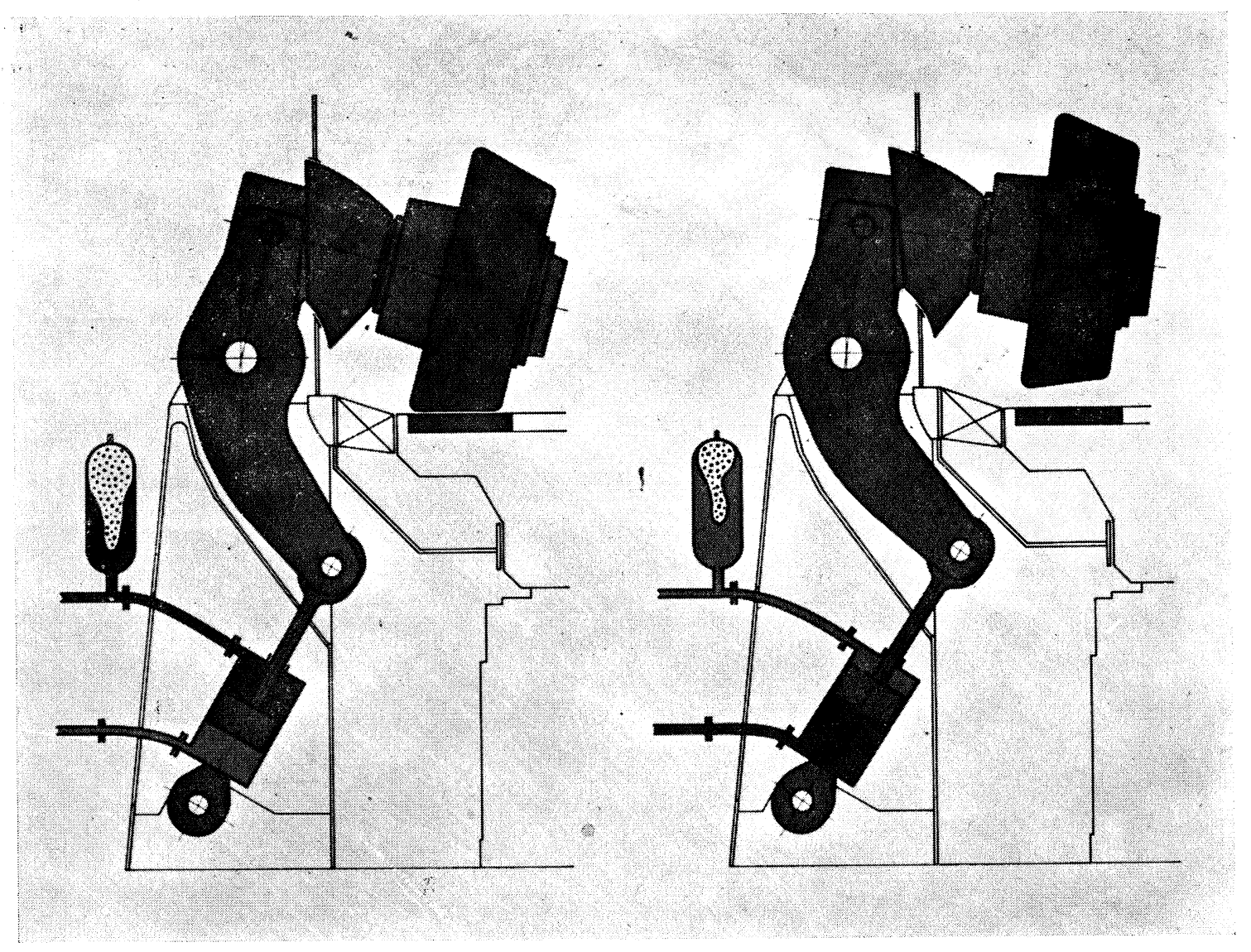

Fig. 7

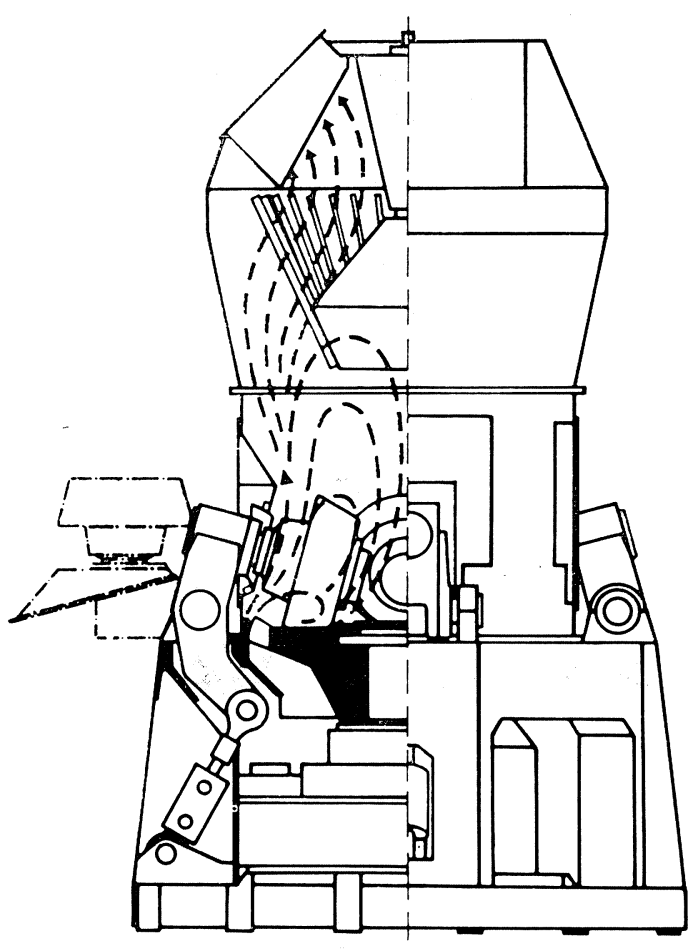

Fig. 8

Al pasar el material entre los rodillos y la pista se produce la molienda por un doble efecto de presión y roce.

La fuerza centrífuga lanza el material molido hacia la periferia del plato, donde es recogido por la corriente ascendente de gases que penetran en la cámara de molienda por la corona de álabes.

Las partículas molidas son succionadas desde la parte superior a través de un separador dinámico montado sobre el cuerpo del molino. La aspiración se realiza mediante una soplante o ventilador de forma que todo el circuito trabaja en depresión.

Las paletas del separador rechazan las partículas más gruesas, que vuelven a caer sobre la pista para ser molidas de nuevo. Modificando las revoluciones del separador se regula la finura del material.

Pero siguiendo con sus preguntas, pasemos a la siguiente: 
¿No decían que el molino vertical sólo sirve para determinados tipos de materiales?

Quizá sea esta cuestión una de las más debatidas en los últimos tiempos, a todos los niveles, cuando se trata de elegir entre un sistema u otro de molienda de crudo. Se oye, por ejemplo, con frecuencia, que el molino vertical no es apropiado para moler materiales con un alto contenido en sílice.

Al hablar de silicatos hay que distinguir entre tres tipos, que podríamos definir así:

Tipo A anhídrido silícico combinado.

Tipo B anhídrido silícico libre con granulometría entre 0-150 micrones, con anhídrido silícico combinado.

Tipo C anhídrido silícico libre —cuarzo- con granulometría de 1-10 mm.

Como Vds. saben, la calcinación del clínker de cemento portland precisa en el crudo del 21-23\% de $\mathrm{SiO}_{2}$ (libre de pérdidas por calcinación). El portador de $\mathrm{SiO}_{2}$ es la arcilla, que es la que proporciona al mismo tiempo el $\mathrm{Al}_{2} \mathrm{O}_{3}$ y el $\mathrm{Fe}_{2} \mathrm{O}_{3}$. Esta arcilla se mezcla con una caliza o con unas margas.

Ocurre, sin embargo, que las arcillas no tienen normalmente el suficiente $\mathrm{SiO}_{2}$ que garantice la obtención de un cemento de primera calidad, y hay que recurrir a un aditivo rico en sílice que nos sirva de corrector, utilizándose normalmente la arena de cuarzo con un contenido del 90 al $98 \%$ de anhídrido silícico libre.

Nunca existieron problemas de proceso con un crudo de alto contenido en sílice molido en molinos verticales; los químicos determinaban el contenido total de $\mathrm{SiO}_{2}$ que necesitaban, y, cuando el valor obtenido coincidía con el valor teórico, el asunto estaba resuelto. Solamente en los últimos años se prestó especial atención al residuo en el tamiz de 125 micrones, observándose la regla de que el contenido de anhídrido silícico sobre este tamiz, referido a la cantidad total de harina, no debería sobrepasar un determinado tanto por ciento, ya que si el cuarzo no está suficientemente molido reacciona con dificultad con los demás componentes del crudo, pudiendo presentarse durante la cocción un aumento de la cal libre.

Se han realizado numerosos estudios comparativos en relación con las finuras obtenidas con un mismo crudo molido en molino de bolas y en molino vertical, y en todos los casos el residuo sobre 125 micrones es menor en el molino vertical que en el molino de bolas, por lo que no puede achacarse al primero una influencia negativa sobre la composición mineralógica del clínker, al realizarse el proceso de calcinación en el horno.

Otro asunto es el relativo al desgaste del molino como consecuencia del contenido en sílice. Sobre este tema hemos tratado ya anteriormente, $y$, sin embargo, hay que tener muy presente que solamente los silicatos del tipo C, es decir el anhídrido silícico libre -cuarzo-, tiene una influencia decisiva en el desgaste de los elementos de molienda, ya que los silicatos del tipo A y B son de por sí tan finos que, prácticamente, no se muelen y son absorbidos por la corriente de gases nada más entrar en el molino.

No hay, por lo tanto, ningún material que, por razones técnicas de proceso, no pueda ser molido en un molino vertical para su posterior utilización como harina de crudo que alimente un horno rotativo para la fabricación de clínker de cemento.

Señores, esto es lo que ha ocurrido en estos últimos años con los molinos verticales en la industria del cemento, y éste es el por qué del cambio que se está produciendo en el sistema tradicional de molienda de crudo. Pero para terminar, quisiera mostrarles algunos detalles de lo que consideramos que siendo ya una realidad, es, sin embargo, el principio del futuro. Nos referimos a los adelantos conseguidos en relación con la automatización, el control y el mando de estas instalaciones. 
Cada proyecto es un caso diferente que debe de ser estudiado con todo detalle. A la vista de los datos de que se dispone, se realiza un esquema de la instalación y de su regulación, como el que muestra la figura 9, que corresponde a una molienda combinada con un horno de $2.000 \mathrm{t} /$ dỉa nominales, y que puede llegar a producir hasta las $2.400 \mathrm{t} /$ día. Como la humedad del material oscila entre el 6 y el $10 \%$ se ha previsto la adición suplementaria de agua en la torre de enfriamiento, así como la aportación de calor mediante un hogar LOMA que sirve también para secar el crudo en el arranque, cuando no se dispone todavía de los gases calientes procedentes del horno.

En este caso se han previsto los siguientes bucles de regulación:

- Regulación de la temperatura a la salida del molino, manteniéndola constante mediante la adición de más agua en la torre de enfriamiento, si disminuye la humedad del crudo o aumenta la aportación de calor de los gases de salida del horno; o la adición de calor a través del hogar LOMA, si se produce la situación inversa. En el caso de marcha directa se regula, por el mismo sistema, la temperatura a la entrada del electrofiltro.

- Regulación de la presión detrás de la soplante del horno, para mantenerla constante, mediante el accionamiento de la válvula de aire frío que permite la entrada de aire directamente al molino o a través del hogar LOMA. En marcha directa se actúa sobre la soplante del molino.

- Regulación del caudal de gases a la salida del molino, que se mantiene constante, actuando sobre la aspiración de la soplante o modificando las revoluciones de la misma.

- Regulación de la alimentación en función de la diferencia de presión antes y después del molino.

Definidas las regulaciones, se desarrolla cada una de ellas hasta determinar los aparatos que las componen, así como su ubicación tanto en el armario del molino, como en la sala de mando central.

Pueden verse también en la figura 9 algunos de los controles previstos, como son:

- la presión detrás del filtro;

- las oscilaciones de la soplante y del molino;

- la presión de trabajo del sistema oleohidráulico de los rodillos;

- la temperatura detrás del hogar LOMA.

Controlándose también, aunque no figuren en ella:

- la temperatura del aceite de lubrificación de los rodillos:

- la temperatura del cojinete antifricción;

- las revoluciones del separador;

- la posición de los rodillos;

- el cierre de tres esclusas;

- el caudal y la temperatura del aceite del reductor.

Junto a este conjunto de regulaciones y controles, se realizan además toda clase de medidas eléctricas, tanto de los motores principales, como de los auxiliares, completándose así, con las protecciones correspondientes, el cuadro eléctrico de la instalación que puede incorporarse, en todo o en parte, al cuadro central de mando. 


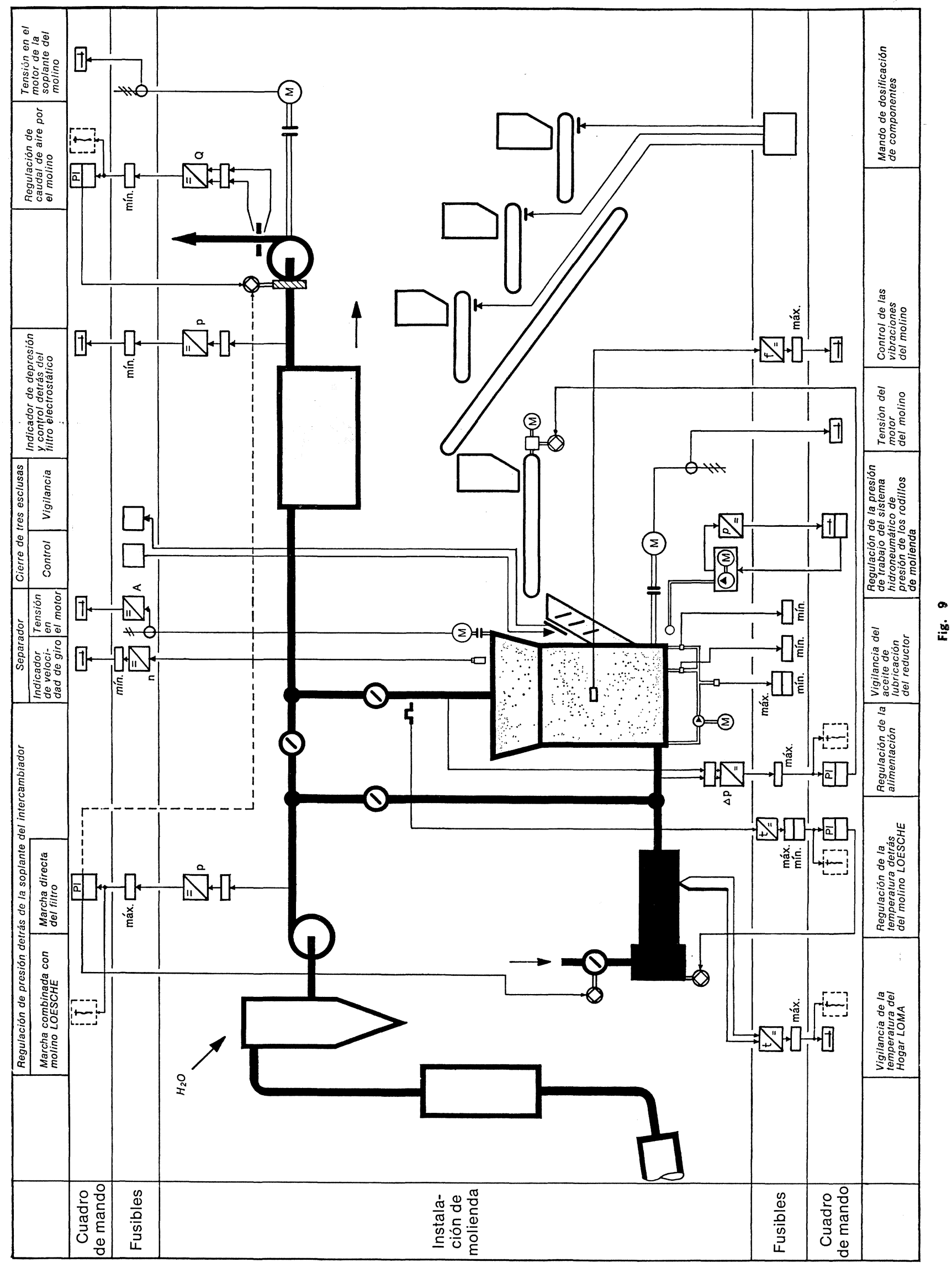


La figura 10 muestra cuatro alternativas de marcha:

A. Marcha directa.

B. Marcha combinada con $6 \%$ de humedad en el crudo y $160.000 \mathrm{Nm}^{3} / \mathrm{h}$ de gases de salida del horno, equivalentes a 2.400 t/día de clínker.

C. Marcha combinada con $10 \%$ de humedad en el crudo y $130.000 \mathrm{Nm}^{3} / \mathrm{h}$ de gases de salida del horno, equivalentes a 2.000 t/día de clínker.

D. Arranque de la instalación trabajando sólo con el hogar.

Los datos del horno, y el balance térmico, permiten determinar las condiciones de funcionamiento en cada uno de los casos que se pueden presentar.

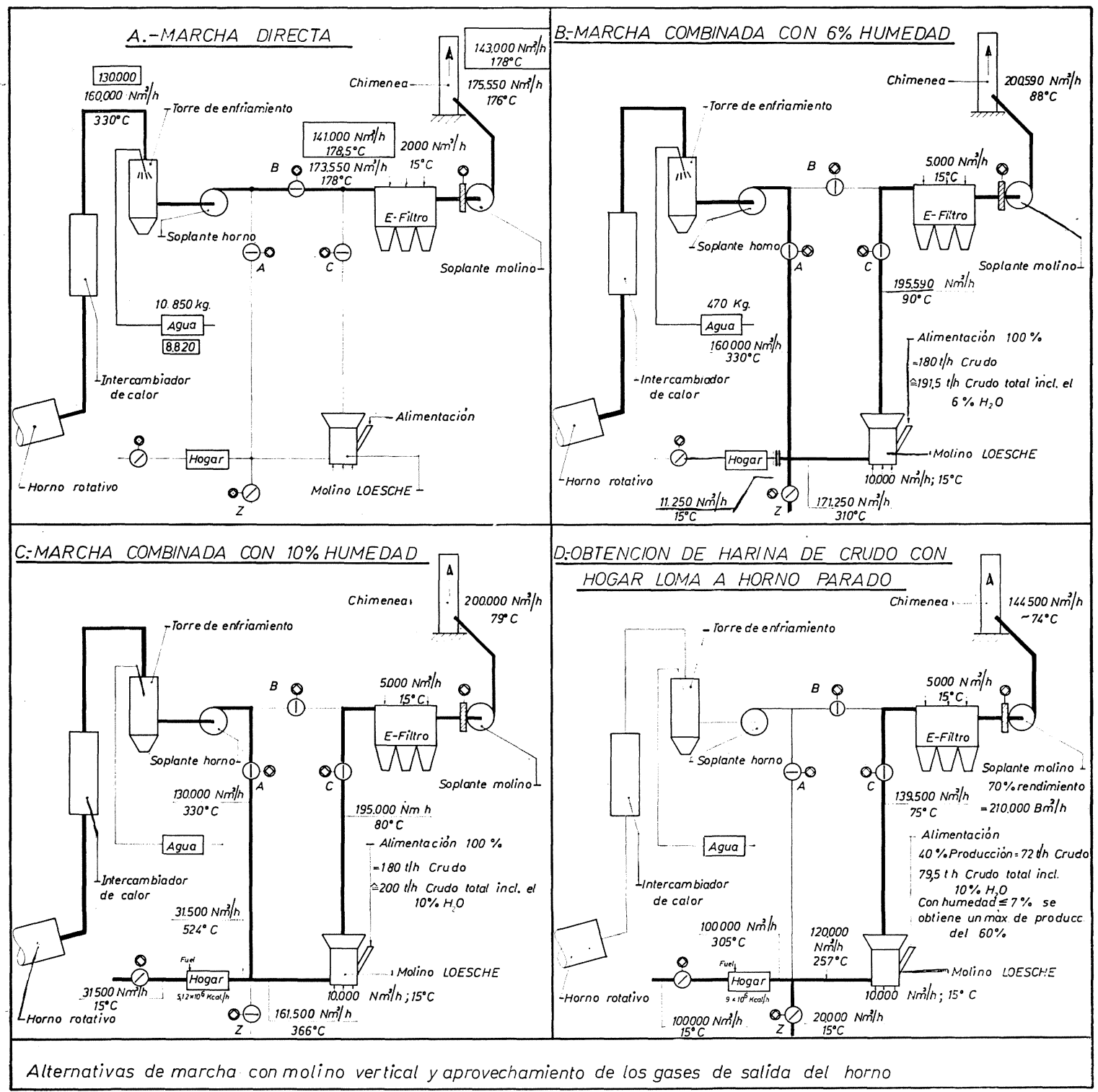

Fig. 10

Definidos todos estos datos, y para alcanzar un grado óptimo de automatización, hay que estudiar hasta en los más mínimos detalles los enclavamientos y las secuencias de arranque y parada. La figura 11 presenta la secuencia en el arranque del molino, trabajando 
sólo con el hogar LOMA, pero esquemas similares se realizan para todos los cambios de marcha que exigen un enclavamiento de todos los motores, y que en este caso son:

1. arranque del molino, trabajando sólo con el hogar (que es el que se ve en la figura);

2. parada del molino, trabajando sólo con el hogar;

3. arranque de la soplante del molino en marcha directa;

4. paso de marcha directa a marcha combinada sin hogar;

5. paso de marcha combinada sin hogar a marcha directa;

6. paso de marcha directa a marcha combinada con hogar;

7. paso de marcha combinada con hogar a marcha directa.

Hay que tener en cuenta que todos estos cambios deberán realizarse no sólo de forma automática, sino sin que tengan influencia en la marcha del horno.

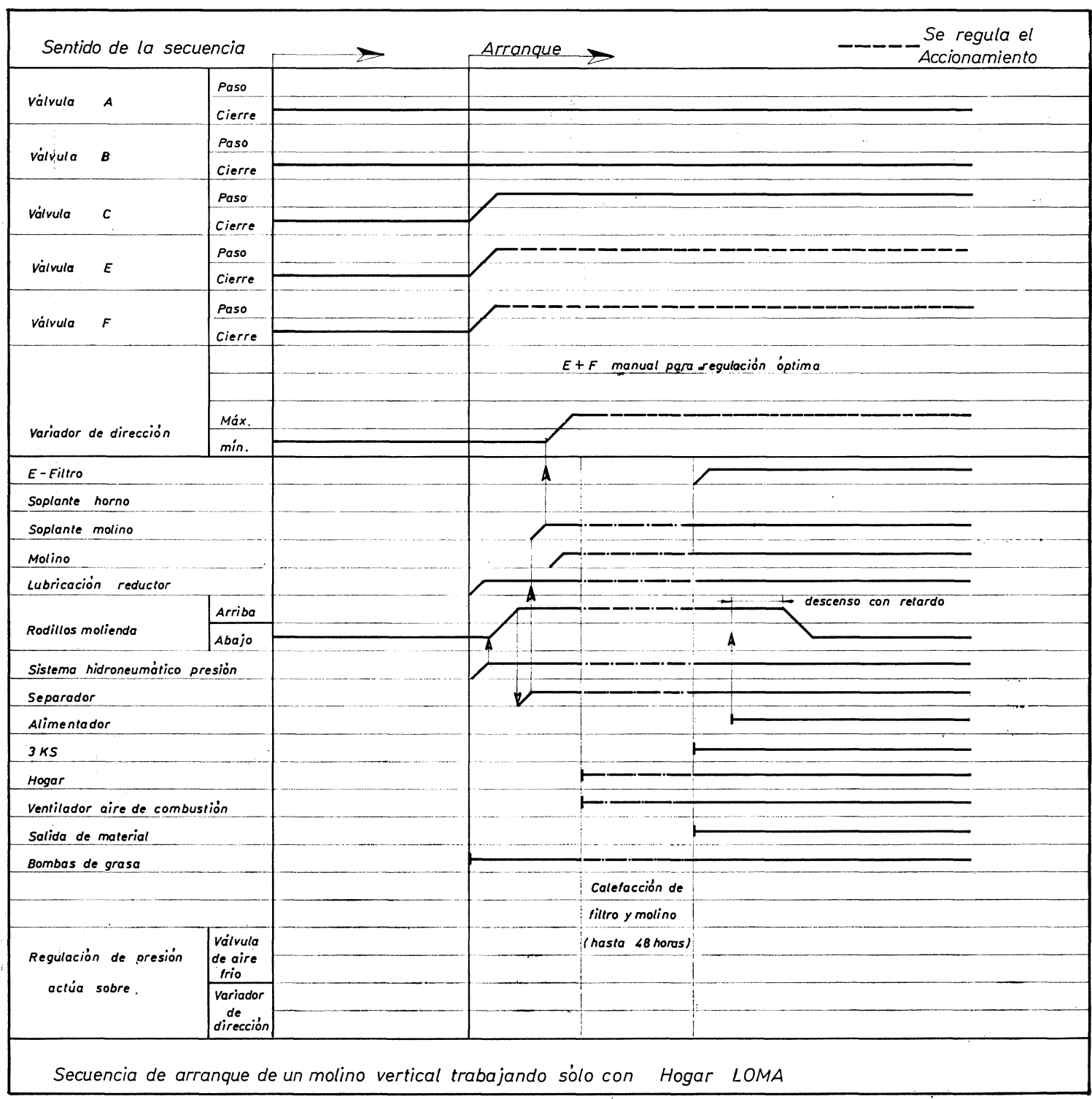

Fig. 11 
Queda por último el capítulo de las alarmas y medidas de seguridad, que garantizan el buen funcionamiento de los equipos, evitando toda contingencia que pueda producir graves averías en la instalación.

Presentamos en la figura 12 un ejemplo de este estudio, referido a la marcha combinada con aprovechamiento de los gases de salida del horno, sin hogar. Estudios similares se realizan para los demás casos, es decir:

- arranque;

- marcha directa;

- marcha trabajando sólo con hogar;

- marcha combinada con hogar.

En la figura se han incluido todas las posibles anormalidades que puedan presentarse, así como los accionamientos que se desconectan automáticamente, bien sea de forma inmediata $(\mathrm{x})$ o a través de un relais de tiempo $(\mathrm{t})$.

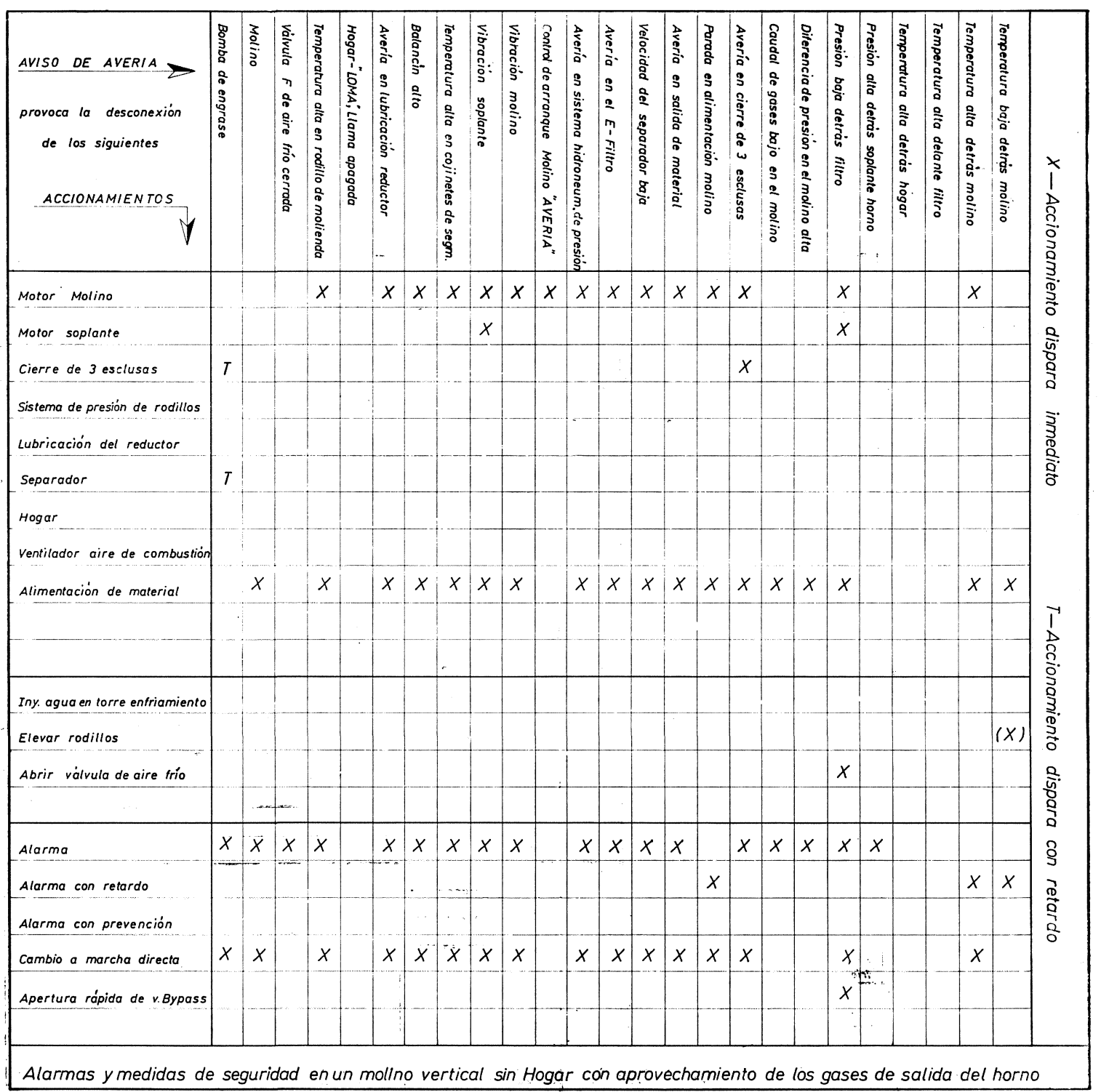

Fig. 12 
Se han indicado también las anomalías que accionan la alarma instantánea o retardada, así como las que actúan sobre el cambio rápido de marcha combinada a marcha directa o viceversa y las que abren instantáneamente el by-pass.

Momentos críticos, como pueden ser el aumento de temperatura del cojinete antifricción o la falta de aceite de lubrificación en el reductor, producen, por ejemplo, la parada instantánea del motor del molino y de la alimentación, al tiempo que suena la alarma y se pasa automáticamente a la marcha directa.

Este ejemplo que les hemos presentado es sólo uno de los muchos casos que funcionan ya repartidos por todo el mundo. La gran capacidad de reacción de los molinos verticales hace que las posibilidades de automatización, regulación y control sean ilimitadas, siendo necesario, sin embargo, reducir estas posibilidades a aquéllas que nos proporcionen un aprovechamiento óptimo de la instalación. Los bucles de regulación, a que antes hemos hecho referencia, han sido definidos bajo esta base; mientras la regulación de la presión detrás de la soplante del horno nos corrige las posibles variaciones en las condiciones del circuito, haciendo que el horno trabaje con completa independencia de lo que ocurra en la instalación de molienda, el control de la diferencia de presión en el molino nos permite optimar el proceso de molturación. La regulación del caudal de gases detrás del molino mantiene las mejores condiciones para la consecución de la producción y la finura deseadas, al tiempo que asegura el buen funcionamiento del filtro que viene también favorecido por la cuarta regulación al permanecer constante la temperatura detrás del molino. Es éste sin duda el campo en el que en los próximos años se producirán los avances más espectaculares, y sobre este tema, así como sobre otros tan importantes, como el desarrollo de los molinos verticales en cuanto a su capacidad de producción o en cuanto a su utilización en la molienda de clínker, esperamos poder informarles nuevamente en los próximos Coloquios, que, con el acierto de siempre, estamos seguros organizará este Instituto Eduardo Torroja, al que felicitamos por el éxito alcanzado y agradecemos la posibilidad que nos ha brindado de estar con Vds. 


\section{COLOQUIO}

1. Lo abrió el Presidente, Sr. ALARCON, quien, para dar tiempo a la producción de intervenciones, comenzó preguntando si los molinos verticales suponían un ahorro notable en cuanto se refiere a obra civil.

La respuesta del Sr. HIDALGO DE CISNEROS fue que sí, y que muy importante, al simplificarse mucho todo el reparto de tuberías como consecuencia, en primer lugar, de que el separador va o puede ir instalado encima del molino, por lo cual, tanto en teoría como en la práctica, no se necesita más edificio que el preciso para soportar el puentegrúa que normalmente se monta para el servicio del molino; y que la experiencia demuestra que queda amortizado sólo con el ahorro que se consigue en el montaje del molino.

Hay que hacer constar —añadió-, que al hacer el proyecto es importante definir dónde va a ir montado el filtro: si encima del molino o a un lado, dependiendo de las disponibilidades de espacio que se tengan.

Si va encima - prosiguió-, hay que soportar el filtro y, en consecuencia, el edificio tiene que ser más compacto y resistente. Pero - concluyó-, lo que es en sí la instalación de molienda no requiere más edificio que el preciso para cubrir el molino (si es que llueve mucho y éste no va al aire) y para soportar la carga del puente-grúa que debe ir encima.

2. A continuación el Sr. CALLEJA hizo una pregunta relacionada con molinos, superficie específica BLAINE y resistencia de los cementos. Dijo haber entendido que, partiendo de un mismo clínker y para obtener un cemento P-450, ello se lograba, en un tipo de molino, con una finura BLAINE de $2.000 \mathrm{~cm}^{2} / \mathrm{g}$, y en otro tipo de molino, con una finura BLAINE de $3.000 \mathrm{~cm}^{2} / \mathrm{g}$. Si la misma resistencia parece no depender $-\mathrm{o}$ parece no depender mucho- de la superficie específica BLAINE — dijo- ¿de qué depende?; ¿quizás de la granulometría del cemento que se obtiene en uno y otro caso?

Respondió el Sr. HIDALGO DE CISNEROS que exactamente así era. Que las granulometrías resultantes en un molino vertical y en otro de bolas son distintas, y que ello hace que las resistencias de los cementos de un mismo clínker obtenidos en uno y otro molino sean también diferentes. Esta pregunta -añadió-, me permite ampliar un poco este aspecto que está aún en fase de experimentación, y en el que tenemos fundadas esperanzas de éxito. $\mathrm{Y}$ prosiguió: al tener la curva granulométrica del cemento una inclinación distinta en el caso do un molino vertical que en el caso de un molino de bolas, el molino vertical da cementos con menos superfinos (y por ello con resistencias diferentes) que el molino de bolas. Yo - dijo-, he hablado de resistencia de un P-450, pero no he dicho si a 3,7 ó 28 días; el problema está en que la resistencia a 3 días —o en los primeros días-del cemento molido en molino vertical quedaba muy por debajo de la del molido en molino de bolas. Para poder tener con aquel resistencias a corto plazo similares a las que se tienen con éste, se puede actuar de forma que la curva granulométrica se desplace adecuadamente y paralelamente a sí misma; pero entonces resulta que la resistencia a 28 días es muy superior a la que se obtiene en un molino de bolas. Esto -añadió-, es un problema en el caso de regir normas que, como las alemanas, fijan un tope máximo de resistencia a 28 días para los cementos, pues conseguir elevar las resistencias 
a los primeros días saliéndose de la limitación impuesta a los 28 no interesa. Otra cosa es en el caso de España dode, por no existir tal limitación, nada importa que un cemento P-450 pueda llegar a dar una resistencia de $600 \mathrm{kp} / \mathrm{cm}^{2}$ a 28 días.

El Sr. CALLEJA trató de precisar aún más, preguntando si, en vista de lo expuesto por el Sr. HIDALGO DE CISNEROS, se podría decir que en el caso de un molino vertical el cemento resultante tiene una granulometría menos dispersa - con menos diversidad de tamaños $\mathrm{y}$, en particular, con menos finos y menos gruesos y con mayor contenido de tamaños intermedios-, o, dicho de otro modo, tendente a ser más "monogranular" que en el caso del cemento obtenido con un molino de bolas.

El Sr. HIDALGO DE CISNEROS dijo que quisiera contestar que sí, pero que prefería hacerlo con la ayuda del Sr. KLATT. En efecto, lo hizo dibujando esquemáticamente en el encerado las curvas de resistencia frente a tiempos para cementos que, o dan la misma resistencia a 3 días (p. ej. $200 \mathrm{kp} / \mathrm{cm}^{2}$ ), o dan la misma resistencia a 28 días (p. ej. $450 \mathrm{kp} / \mathrm{cm}^{2}$ ). En el primer caso, si uno de los cementos da también $450 \mathrm{kp} / \mathrm{cm}^{2}$ a 28 días, éste sería el molido en molino de bolas, por ejemplo a $3.000 \mathrm{~cm}^{2} / \mathrm{g}$ BLAINE; mientras que el otro, que sería el molido también a $3.000 \mathrm{~cm}^{2} / \mathrm{g}$ BLAINE, pero en molino vertical, daría a 28 días $600 \mathrm{kp} / \mathrm{cm}^{2}$. En el segundo caso, si uno de los cementos da también $200 \mathrm{kp} / \mathrm{cm}^{2}$ a 3 días, este sería, evidentemente y como antes, el molido en molino de bolas a $3.000 \mathrm{~cm}^{2} / \mathrm{g}$ BLAINE; pero entonces el otro daría a 3 días una resistencia menor que $200 \mathrm{kp} / \mathrm{cm}^{2}$ y sería el molido en molino vertical a una finura inferior a $3.000 \mathrm{~cm}^{2} / \mathrm{g}$ BLAINE (p. ej. a $2.000 \mathrm{~cm}^{2} / \mathrm{g}$ BLAINE). Esto es -dijo-, lo que quiere decir que las "rectas" resistencia (ordenadas)-tiempo (abscisas) son siempre más inclinadas - de mayor pendiente- para los cementos molidos en molinos verticales que para los molidos en molinos de bolas, y tanto si la finura BLAINE alcanzada con molinos verticales es igual como si es menor -entre ciertos límites- que la lograda con los molinos de bolas. El Sr CALLEJA consideró satisfactorias las respuestas y dió las gracias por ellas.

3. Preguntó después el Sr. MARTINEZ YNZENGA cuántos molinos verticales había instalado la firma LOESCHE, a lo que el Sr. HIDALGO DE CISNEROS respondió que ninguno, ya que se encuentran todavía en la fase experimental aunque, eso sí, a nivel industrial, una vez superada ya la experimentación a escala de laboratorio.

4. El Sr. AGUANEL preguntó qué temperatura se alcanzaba en el molino y en el cemento durante la molienda, y si influía en la deshidratación del yeso.

La respuesta de los Sres. KLATT e HIDALGO DE CISNEROS fue que se molía con aire fresco y que la temperatura de éste a la salida del molino aumentaba como consecuencia del calor de la molienda, siendo normalmente de 40 a $50^{\circ} \mathrm{C}$ en circuito abierto; y más elevada, naturalmente, si la temperatura del clínker a la entrada del molino era ya de 40 a $50^{\circ} \mathrm{C}$.

A la pregunta del Sr. AGUANEL de si esto quería decir que no se producía ninguna deshidratación del yeso, se respondió que con temperaturas del aire a la salida del molino inferiores a $100^{\circ} \mathrm{C}$ no hay deshidratación en absoluto. Añadió el Sr. KLATT que cuando se trata de otros materiales que entran en el molino a 300 ó $350^{\circ} \mathrm{C}$, en la parte superior de la pista de molienda se tienen temperaturas de 80 a $85^{\circ} \mathrm{C}$, porque la superficie aumenta rápidamente dentro del molino y la temperatura baja bastante.

Ante esta explicación siguió preguntando el Sr. AGUANEL si se podría alimentar el molino con clínker a $350^{\circ} \mathrm{C}$, a lo que contestó el $\mathrm{Sr}$. KLATT que sí, y que también en esas condiciones se podía dosificar el yeso, precisamente porque dentro del molino la temperatura baja inmediatamente hasta $70-80^{\circ} \mathrm{C}$, con lo cual se evita la deshidratación. Pero que, además, para cuando la temperatura es demasiado alta el sistema va provisto de un codo por el que se puede introducir de un 0,5 a un $1 \%$ de agua, para mejorar la separa- 
ción del polvo del aire del molino en un filtro electrostático, aunque normalmente el sistema está previsto para montar filtros de mangas.

Como aclaración al hecho de no haber todavía molinos verticales instalados y en producción industrial real, los Sres. HIDALGO DE CISNEROS Y KLATT dijeron que se había hecho una primera prueba a escala real en una fábrica de cemento y durante dos semanas, con un molino vertical del tipo 14 para una producción de 8 a 10 t/hora; y que, en su momento, se haría una segunda prueba para producciones de 50,60 y más t/hora. Añadió el Sr. KLATT que en 1968 se hizo por primera vez una molienda con un molino LOESCHE para obtener el mismo residuo sobre tamiz de 4.900 mallas $/ \mathrm{cm}^{2}$ que con un molino de bolas convencional. El resultado fue un cemento malo que no se ajustaba a norma, habiéndose llegado a la conclusión de que con un molino vertical es preciso llegar a un residuo más o menos de $0,5 \%$ sobre tamiz de $4.900 \mathrm{mallas} / \mathrm{cm}^{2}$, lo que viene a suponer una fracción del orden del $15 \%$ de tamaño superior a 30 micras, en tanto que con un molino de bolas hay que moler, sobre poco más o menos, hasta una fracción del 28 al $30 \%$ mayor de 30 micras.

Siguió preguntando el Sr. AGUANEL si el sistema de molino vertical permite realizar la molienda de cementos siderúrgicos, puzolánicos y compuestos (según el Pliego RC-75), a.. lo que respondió el Sr. HIDALGO DE CISNEROS que tales moliendas podrían hacerse perfectamente y que incluso se podría pensar en una molienda combinada clínker/puzolana, procediendo a la mezcla de los materiales molidos antes de su llegada al silo. Añadió el Sr. KLATT que en el caso de las puzolanas unas veces convenía trabajar con un hogar auxiliar y otras sin él, dependiendo en cada caso del contenido de agua de la puzolana, ya que si es excesivo hay que eliminarlo, al menos en parte.

5. El Sr. BRAVO pidió datos comparativos del consumo energético en molinos verticales y de bolas, respondiéndole el Sr. HIDALGO DE CISNEROS que, según los datos que había aportado, el consumo energético de un molino vertical es inferior al del molino de bolas, como consecuencia del tipo de máquina y del volumen de material que hay que mover en uno y otro caso. La experiencia de moler un mismo material con unos y otros molinos - dijo-, indica que con materiales de difícil molturabilidad el consumo energético es de un 10 a un $15 \%$ menor en el caso del molino vertical; consumo que es menor en un 25 ó $30 \%$ si se trata de otros materiales más fácilmente molturables. Es decir -añadió-, hay una diferencia mínima del $10 \%$ y máxima del $30 \%$ en el consumo, según el tipo de material, y siempre a favor del molino vertical.

6. El Sr. AGUANEL preguntó acerca de la reología de los hormigones con los cementos "monogranulares" de los molinos verticales. El Sr. HIDALGO DE CISNEROS dijo no estar en condiciones de responder, ya que no se había llegado a producir con ellos cemento en cantidad para emplear en hormigones.

7. A continuación el Sr. LOPEZ SOLER expuso las consideraciones siguientes: si las curvas de desarrollo de resistencias con el tiempo tienen distinta pendiente en el caso de un cemento molido en molino vertical - mayor pendiente- que el caso del cemento molido en molino de bolas - menor pendiente-, de tal manera que en el primer caso se consiguiera un cemento que cumpliese con la resistencia mínima exigida a su categoría a 28 días, pero no a 7 y/o 3, es decir, que no satisfaciese los intervalos de crecimiento de resistencia estipulados en las normas, precisamente por la mayor igualdad de granos -menor dispersión de tamaños- y el distinto desarrollo de la hidratación que en el caso del cemento tradicional molido en molino de bolas ¿qué pasaría?

El Sr. HIDALGO DE CISNEROS repitió que ese era precisamente uno de los problemas para introducir los molinos verticales en la molienda del clínker; que si se consigue - sin gran margen - la resistencia mínima de una categoría a 28 días, no se alcanzan 
las mínimas estipuladas para edades más cortas; y que, por otra parte, al moler de forma que se alcancen éstas, se rebasa con gran margen la mínima exigida a 28 días, lo cual, según las normas alemanas que fijan asimismo una limitación superior o máxima a dicha edad, es también un inconveniente, pues puede suponer también salirse de la norma. No es inconveniente, en cambio, en países que - como España- admiten que un cemento P-450 pueda dar a 28 días una resistencia de $600 \mathrm{kp} / \mathrm{cm}^{2}$. A esto dijo el Sr. LOPEZ SOLER que eso era cierto, pero que era de presumir que con el tiempo se impusieran limitaciones superiores de resistencia en casi todos los países y que en tal caso el desarrollo de resistencia de los cementos molidos en molinos verticales podría no encajar en ninguna norma.

Este problema - continuó el Sr. HIDALGO DE CISNEROS-, es difícil de resolver, por ser también difícil cambiar las inclinaciones de las curvas, ya que éstas son en cierto modo reflejo de las curvas granulométricas de los cementos.

8. El mismo Sr. LOPEZ SOLER volvió sobre el tema del consumo energético unitario, en relación con lo anterior. Dijo: supuesto que una tonelada de cemento de una determinada categoría exige un consumo dado cuando es molida con molino de bolas, y supuesto que la misma tonelada y categoría —esta última en lo que se refiere a resistencia a 28 días y sin considerar las de edades anteriores- exige otro consumo con un molino vertical ¿cuál sería la diferencia de consumos, admitiendo que en ambos casos se llega a obtener la misma superficie específica?

Los Sres. KLATT e HIDALGO DE CISNEROS respondieron que la diferencia -a favor del molino vertical- era del orden de $29 \mathrm{kWh} / \mathrm{t}$ para una superficie específica BLAINE de unos $2.600 \mathrm{~cm}^{2} / \mathrm{g}$, y para una resistencia a 28 días de $475 \mathrm{kp} / \mathrm{cm}^{2}$, según norma DIN, equivalente a $575 \mathrm{kp} / \mathrm{cm}^{2}$ del cemento tipo III, según norma ASTM.

9. En la misma línea, el Sr. MARTINEZ MARTINEZ preguntó si el ahorro energético oscilante entre el 10 y el $30 \%$, que según el Sr. HIDALGO DE CISNEROS se obtiene dependiendo del material, se logra cuando -en relación con un molino de bolas- se opera a igual resistencia a 28 días (y menores resistencias a 3 y/o 7 días), o cuando se opera a iguales resistencias a 3 y/o 7 días (y mucho mayor resistencia a 28 días).

El Sr. HIDALGO DE CISNEROS respondió que los ahorros mencionados se referían a crudos, y que para cemento se habían dado cifras concretas de $29 \mathrm{kWh} / \mathrm{t}$ para moler a $2.600 \mathrm{~cm}^{2} / \mathrm{g}$ BLAINE y con resistencia de $475 \mathrm{kp} / \mathrm{cm}^{2}$ (DIN). Y que, por otra parte, con el mismo consumo energético específico en un molino vertical y en otro de bolas las resistencias de los cementos resultantes se igualan -0 tienden a igualarse- a 28 días, pero no a 2 ó 3 (ó 7) días, quedando a estas edades las del cemento del molino vertical por debajo de las correspondientes al cemento del molino de bolas.

10. El Sr. ABRISQUETA preguntó después en relación con la producción y la potencia de los molinos verticales, siéndole contestado que el más grande en marcha está produciendo $420 \mathrm{t} / \mathrm{h}$ con una potencia de $3.000 \mathrm{~kW}, \mathrm{y}$ que hay en proyecto otro con capacidad para $650 \mathrm{t} / \mathrm{h}$. Añadió el Sr. ABRISQUETA que, dada la enorme producción de los hornos actuales (6.000-8.000 t), no hay capacidad suficiente de molienda de crudos para ellos con los molinos de bolas, si no es a base de una cadena de ellos, y que creía que la solución estaba en los molinos verticales.

A esto respondió el Sr. HIDALGO DE CISNEROS que así era, y que en Grecia se está poniendo en marcha un horno de 4.200 t/día con un solo molino vertical de 420 t/hora. El Sr. ABRISQUETA añadió que aunque esto no es lo normal, puesto que en proyectos recientes se va a la solución de dos molinos en batería y no a un solo molino vertical, sin embargo esto último es lo lógico, dado además el ahorro en obra civil del que se había hablado al principio 
El Sr. HIDALGO DE CISNEROS estuvo de acuerdo y dijo que a los clientes de LOESCHE que consultaban sobre instalaciones de molienda para hornos de $6.000 \mathrm{t}$, y en proyectos que la firma hacía en tales condiciones, ésta ofreció siempre un solo molino vertical, o dos por seguridad de marcha u otras razones del cliente, habida cuenta de que - respondiendo a otra pregunta del Sr. ABRISQUETA - el tamaño del molino no influye en la calidad ni en la finura del crudo, siendo éste el mismo en cualquier caso.

11. A continuación el Sr. FERNANDEZ MOLINA hizo una aclaración sobre el molino vertical y la finura de molido a la que antes se había hecho referencia. Dijo: antes se ha hablado de que un cemento portland normal molido en molino vertical debía tener un $15 \%$ de partículas mayores de 30 micras, es decir, un $85 \%$ de partículas menores de dicho tamaño, lo cual, para una distribución granulométrica más o menos normal, supone una cantidad importante - del orden del $46 \%$ - de partículas finas inferiores a 10 o a 7,5 micras, que puede plantear problemas graves en la utilización del cemento.

El Sr. HIDALGO DE CISNEROS aclaró a su vez que la distribución granulométrica es distinta que la de un cemento de molino de bolas, pues aun cuando el $80 \%$ sea inferior a 30 micras, en él hay menos finos que los que daría un molino de bolas para la misma finura global, debido al hecho de que la curva granulométrica del cemento del molino vertical es mucho más inclinada que la del cemento del molino de bolas, existiendo en el caso de aquél una concentración de partículas o tamaños alrededor de las 20 micras.

Ante la nueva pregunta del Sr. FERNANDEZ MOLINA sobre el tamaño medio de partículas conseguido en el molino vertical, el Sr. KLATT contestó que lo que se trata de conseguir con un tipo dado de molienda, más que una superficie específica o una granulometría total dadas, es concentrar el mayor número de partículas posible en la zona óptima -a efectos de resistencia - de la curva granulométrica; y que, según estudios que se están llevando a cabo en Alemania, dicha zona óptima, en la que debe concentrarse el mayor número posible de partículas, es la situada entre 10 y 15 micras.

12. El Sr. LORENZO SITGES insistió finalmente sobre el aspecto relativo a la reología del hormigón, suscitado antes por el Sr. AGUANEL, diciendo que para él tenía una gran importancia, ya que el único fin del cemento es servir de materia prima para el hormigón. Y que, por lo tanto, si el cemento molido en molino vertical tuviera en tal sentido algún inconveniente, no serviría; por lo cual era preciso saber si tal cemento podía influir, mejorando o empeorando, las propiedades del hormigón en cualquier aspecto.

Respondió el Sr. HIDALGO DE CISNEROS que estaba de acuerdo con ello, y que en los institutos alemanes del cemento y del hormigón se estaban llevando a cabo los estudios oportunos para poder establecer las conclusiones correspondientes.

Y no habiendo más preguntas sobre el tema, el Presidente, Sr. ALARCON CANDEL, agradeció la participación y presencia de todos en el Coloquio, el cual dió por terminado, levantando la sesión. 